\title{
THE ROLE OF BUSINESS INTELLIGENT SYSTEMS IN MONITORING AND ANALYSIS OF UNIVERSITY DATA

\author{
Melina Neykova $^{1}$ Boyanka Zhelyazova $^{2}$
}

\begin{abstract}
Nowadays, it has become clear that the success of different sized organizations depends on the speed at which they adapt to the dynamic changes and challenges of competitive market structures. At the same time, it is considered that information is a key element for identifying the strengths and weaknesses of the business activities of organizations and the trends for their future development and market consolidation.

Modern universities face major challenges related to the processing of large amounts of data, which are continuously generated by different systems and units, but in most cases, the information flow is not analysed effectively enough. Namely the efficient extraction of educational data is an important aspect for the analysis of the state of the university as well as the effective planning of its future development.

Therefore, the main purpose of this study is to consider the capabilities of intelligent business analysis information systems to monitor and control the large volumes of data generated at the University of Forestry, Bulgaria. Implementing such a system will help transform data into valuable information and knowledge that will assist academic leadership in taking timely, informed, reasoned managerial decisions and actions, taking into account the dynamic and competitive educational environment and rapidly changing educational needs in higher education.
\end{abstract}

UDC Classification: 004.02, DOI: https://doi.org/10.12955/pns.v1.121

Keywords: business intelligence systems, university data analysis, support management decisions

\section{Introduction}

Modern universities are developing in a dynamic, competitive educational environment. They face serious challenges related to the processing of large amounts of data that are continuously generated by different systems and units. In keeping with the claim that information is a key element that contains answers to the strengths and weaknesses of organizations' business activities, as well as the trends for its future development and consolidation to the market, it can be said that the effective extraction of educational data is an important aspect for the analysis and effective planning in the development of educational structures. Unfortunately, the large information flows that are generated are in most cases not processed efficiently, so that their analysis will lead to a clear assessment of the status and priorities of the organization's development, as well as to planning and extrapolating the data.

In line with the claim that the success of different sized organizations depends on the speed at which they adapt to the dynamic changes and challenges of competitive market structures, the key measures that can be taken are the implementation of a comprehensive strategy for deploying business intelligence applications and technology tools that can be used to study patterns and trends in educational data and information. Adopting such a strategy as a result will increase both the quality of educational and research processes in higher education and the economic aspects of managing their public resource.

In this sense, the presented article is aimed to study the capabilities of intelligent information systems for business analysis in order to monitor and control the large volumes of data generated at the University of Forestry in Bulgaria. Implementing such a system will help transform data into valuable information and knowledge, that will assist academic leadership in taking timely, informed, grounded management decisions and actions, given the dynamic and competitive educational environment as well as the rapidly changing educational needs of higher education. In addition, business analytics technologies and dynamic process research solutions will help give a fuller picture of the University of Forestry's development at the specific time of analysis by integrating data generated from different sources, which will help support the process of rethinking the development of the university's vision and the presentation of its positions among educational structures.

\section{Literature review}

The importance of Business Intelligence technologies and their development are directly related to the challenges that different organizations face in the process of collecting, processing and storing huge

\footnotetext{
${ }^{1}$ University of Forestry, Faculty of Business Management, Department of Computer Systems and Informatics, Bulgaria, e-mail: mneykova@ltu.bg;

${ }^{2}$ University of Forestry, Faculty of Business Management, Department of Computer Systems and Informatics, Bulgaria e-mail: bzhelyazova@ltu.bg
} 
amounts of data, whose tendency is to grow steadily. This is why organizations often have difficulty converting the accumulated amounts of data into useful information and transmitting them to the higher management team in a timely manner. It is known that the success of modern companies depends on the speed at which they adapt, so the company manager needs accurate information, analysis and visualization through various real-time business analysis software tools to properly assess the status and the priorities of the development of the company and make effective management decisions. As a result, the organizations today are forced to look for the right technological solutions and software tools to collect, transform and analyse large amounts of data in real time (Wen-Chen, 2014).

In this sense, Business Intelligence systems today provide applications and technologies, which help companies to acquire more extensive and thorough knowledge of their own business activities and the results they have achieved (Dell'Aquila et al., 2008). The main purpose of Business Intelligence technology systems is to provide various levels within organizations with timely, relevant and easy to visualize and use business information that can be effectively analysed in order to support and improve the managerial decision-making process across a wide range of business activities (Elbashir et al., 2008). In this way, Business Intelligence systems support the analytical decision-making process by performing multifunctional data analysis, which provides a full picture of the business activities of different sized organizations.

The new intelligent analytical applications and visualization technologies are constantly developing and improving, allowing managers to perform real-time statistical analysis and forecasting of business processes and to meet today's business requirements (Ramakrishnan et al. 2012; Howson et al., 2019). They provide the management of the companies with an effective way of presenting a multidimensional description of data through tools for quick extraction, transformation, organization, analysis and summary of a large amount of business information (Shariat \& Hightower, 2007; Watson \& Wixom, 2007; Yeoh \& Koronios, 2010; UL-Ain et al., 2019). This trend has been addressed in numerous reports and academic studies that show BI solutions as an important element present in the list of companies' priority technologies. In addition, BI tools are focused on aggregating data from different sources, which increases the efficiency of data and information processing, making it possible to perform more in-depth and comprehensive analysis, which facilitates better decision-making and the overall development of the company.

In this sense, BI platforms are becoming an increasingly strategic tool that boosts the competitive advantage of the organization (Watson \& Wixom, 2007), where Business Intelligence capabilities are becoming important functions that support the organization both in the process of innovating and increasing performance (Yeoh et al., 2008). This strategic tool must be coordinated and integrated with the business space and the decision-making environment used in the organization and it is exactly this proportion that is the key to the success of business intelligence (Clark et al., 2007). The integration of BI solutions with other systems is a very necessary function, whose capabilities can impact BI success in different decision-making environments. For this purpose, the process is implemented at the data, application, and user levels (Isik et al., 2013). Since BI platforms are based on the processing of operational data, which are collected and stored sequentially (Saha, 2007), many software companies offer BI systems that are an extension or integral part of embedded ERP systems, such as Microsoft's SQL Server, SAP's Business Objects BI Suite, and IBM's Cognos BI.

At the same time, with the introduction of BI systems, modern companies increasingly tend to look for specialists who have the skills and knowledge to work with software platforms and technologies for in-depth multi-dimensional analysis of the increasing volumes of specific business information. This trend is driven by the growing demand and deployment of business intelligence platforms (BI) and analytics platforms which are characterized by easy-to-use tools that support a full range of analytic workflow capabilities and do not require significant involvement by IT specialists in order to predefine data models upfront as a prerequisite for analysis (including when implementing enterprisescale deployment) (Sallam et al., 2017; Neykova\& Zhelyazova, 2017). In this regard, according to International Data Corporation (IDC, 2019) forecasts, global revenue for big data and business analytics solutions is expected to reach \$ 189.1 billion in 2019 and double-digit annual growth in 2022 .

Although Business Intelligence platforms are designed to serve a variety of business organizations, they are necessary and applicable in higher education, as educational institutions already have organizational 
structures in place and data warehouses that are comparable to that of large organizations (Muntean et al., 2010). In this sense, the leading educational institutions are aware that in order to maintain their position in the market, they need to look for approaches and tools to analyse and transform data into valuable information and knowledge. The main purpose of implementing a business intelligence system in higher education is to support the decision-making process at all management levels through in-depth analysis and integration of data generated from various sources, which will serve to trace the educational and management process. Simultaneously the implementation of such a system will contribute to the preparation of up-to-date reports by employees working in the basic, primary and service units, whose analysis has so far been hampered by multiple "hand-to-hand" interventions and lack of scalability, which makes data vulnerable to error, and analysis and solution-finding difficult. Thus, in the process of adopting a comprehensive strategy for deploying business intelligence applications and technology tools that will be used to study patterns and trends in educational data and information, it is important to pay attention to Monfared's statement that "the quality of data on business intelligence systems showed the strongest relationship with the quality of decision making", or there is a direct relationship between the process of improving the quality of the data, including the internal or external data source, the type of data in quantitative or qualitative terms, the reliability of the data and the perceptions of the one who used the business intelligence system, where the end result is improved decision-making (Monfared \& Akbari, 2019).

\section{Discussion}

Nowadays, educational institutions are aware that they need to thoroughly analyse the data that reflect the educational and management process. That is why the implementation of business intelligence systems plays an important role in the monitoring and control of university data in educational structures. The establishment and implementation of an intelligent information system at the University of Forestry will contribute to the systematic extraction and creation of multidimensional analyses and associations of relationships in educational information arrays so that data can be tracked, visualized, and managed. In particular, the successful development and implementation of a business intelligent system at the university will support key areas such as: administrative and management activities; training and research; relationship management with alumni. The developed business intelligent solution may initially cover only part of the available data (for example, related to finance and personnel management), and subsequently to expand its application to other functional areas (Figure 1) such as:

1. Monitoring and analysing data generated as a result of annually performed student recruitment campaigns with follow-up results and evaluation of students who have been accepted at the university. Using the possibilities to create associations of data relationships in order to visualize the overall picture by comparing data from previous years. Simultaneously tracking the development of the enrolled students in the specialties, as well as their future realization. Managing relationships with alumni, including analysing and tracking information arrays from the University's Alumni Network system (Mladenova \& Kirkova, 2019).

2. Monitoring and analysing data generated as a result of teaching activities in order to track, optimize the workload of teaching staff, compare with previous periods, and perform future planning and distribution.

3. Monitoring and analysing data generated as a result of research work and participation in projects of both a specific faculty and individual departments and faculties.

4. Monitoring and analysing data generated by the e-learning platform Blackboard Learn (Mladenova \& Zhelyazova, 2016), which is a constant source of data and information on students' e-learning. In addition, given the international crisis caused by the global COVID-19 pandemic, the Blackboard Learn platform is an instrument of vital importance providing student instruction via distance learning.

5. Monitoring and analysing data generated by the document management system implemented at the University of Forestry - Archimedes system, which manages the processes related to the registration of documents, their movement in the various departments of the university, monitoring of deadlines and their compliance, control over related tasks, maintenance of electronic archives from scanned images of documents and more. The system is a generator of a continuous stream of data that could be the basis for conducting BI analyses in order to visualize, track and optimize the administrative activities at the university. 
6. Monitoring and analysing data generated by accounting activities in order to manage the information available from current and periodic accounting. Creating data relationship associations to visualize the overall picture by comparing data from previous years.

7. Monitoring and analysing data generated by the human resources department in order to manage the available staff cost information. Configuring the structure of the overall analysis to cover the more important groups of indicators, namely indicators of employee motivation; staff recruitment and selection indicators; basic pay ratios; work efficiency; development of human capital.

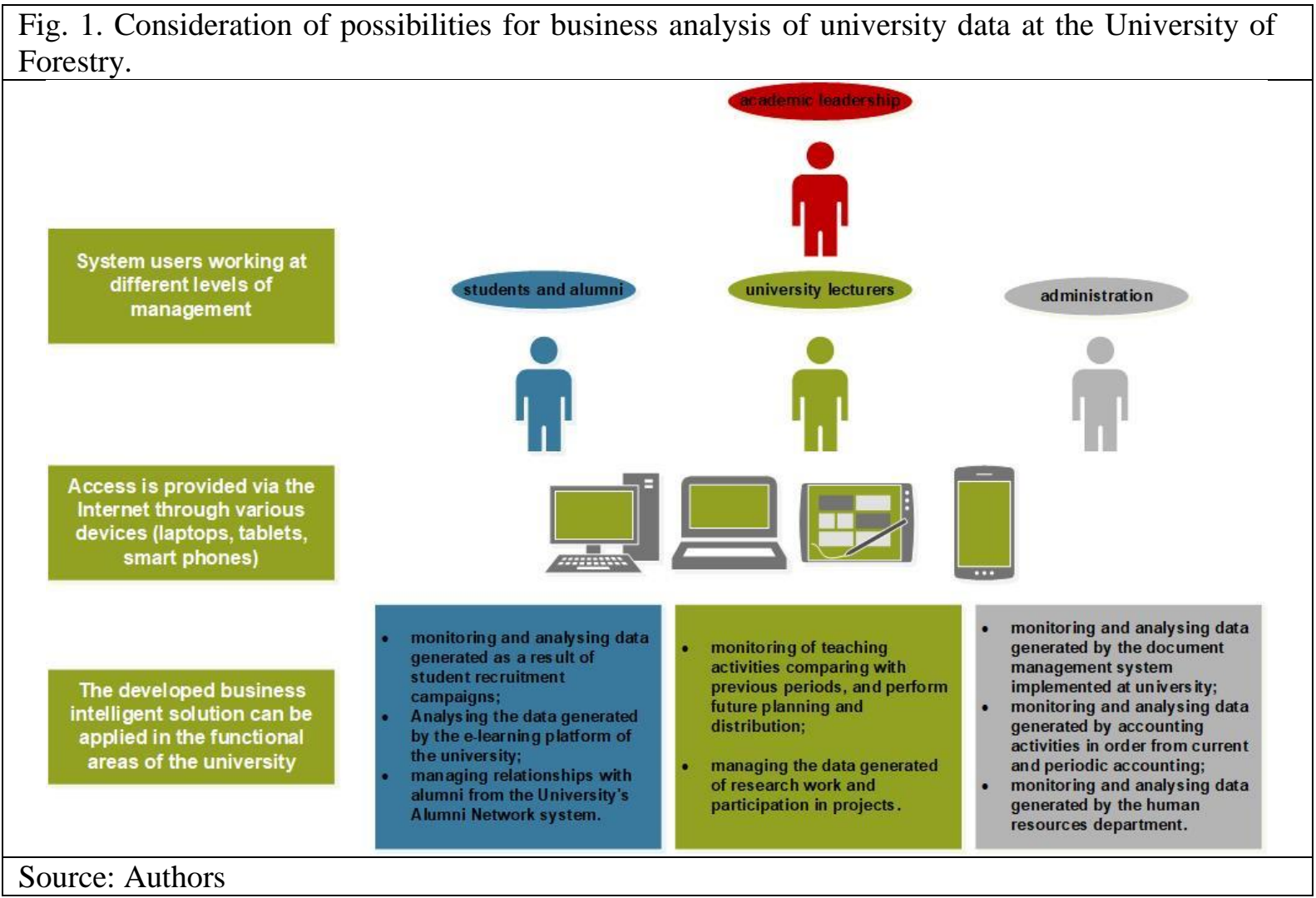

\section{Methods}

The developed business intelligence systems ensure the generation of interactive dashboards, on which the values of key indicators are constantly monitored and controlled, which provide important information about the organization in summary form, reflect the current situation and alert to the presence of potential problems at a very early stage. The dashboards should be designed to be easy to understand, relevant, strategic, quantitative and current. They must include graphical key performance indicators to help visualize detailed information on the change of the values, as well as their generalization.

In this regard, in order to illustrate the importance and role of BI tools in the activities of the University of Forestry, this paper presents an associative analysis based on data from the financial statements for the activity of the organization for the period from 2011 to 2018, which are presented and available on the university website (official website of the University of Forestry: https://ltu.bg). An ETL (extract, transform, data loading) process was performed as a basic step in normalizing the data into a common framework and allowing the creation of associative relationships between data. The module allows fast retrieval of information and generation of personalized reports and real-time analytical processing (Figure 2). The analysis extracted only individual accounting elements that track the trend of the financial and non-financial assets of the university from 2011 to 2018, and based on the loaded data, dashboards were generated with various types of objects that support the visualization of information (Figure 2). The virtual dashboard is interactive and allows the extraction of information in much more detailed sections and the user is able to control the creation of both the interpolation and extrapolation of data. The possibilities for adding and combining different types of diagrams in one virtual board are practically unlimited and depend on the needs and the hierarchical position of the decision maker. With 
the help of the method for analytical processing of this data in real time it is possible to analyse the assets of the organization in the studied period, as the user is able to control the various objects of visualization, as well as to filter the data according to his interest.

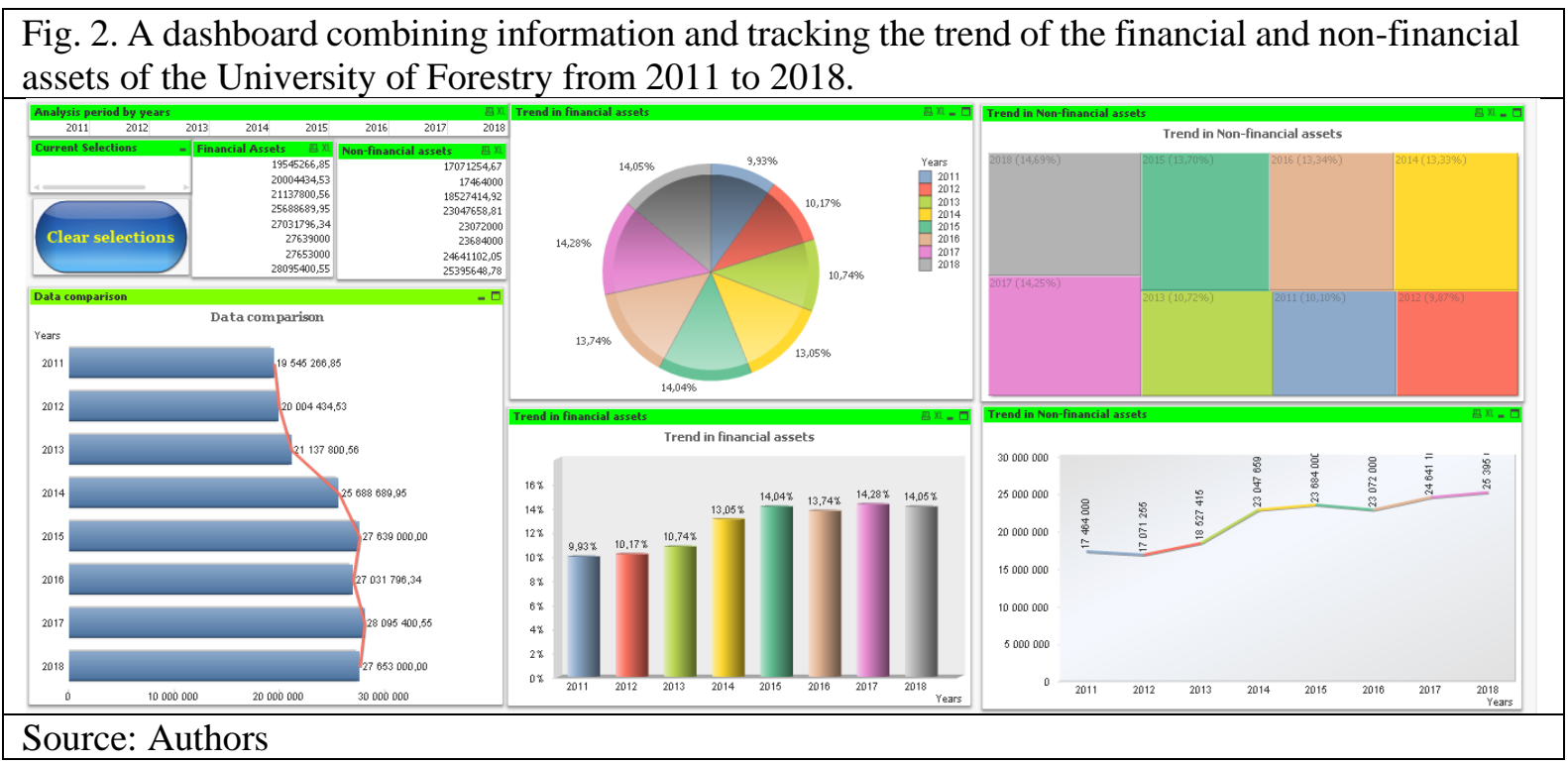

The used BI software is QlikView, which is one of the leading software solutions currently available on the market for business intelligence products, taking the lead in the "quadrant of leaders" in the Gartner report for the next 10 years (Richardson et al., 2020). This product has been used under an agreement concluded between the University of Forestry and QlikTech (Neykova \& Zhelyazova, 2017). The software generates an instant result from the analysis of large amounts of data and creates associative relationships and relationships that help to visualize a clearer overall picture. The user interface is designed in accordance with the specific needs of system users working at different levels of management, providing opportunities to customize reports and references, and develop non-standard specialized reports. Access to the platform is provided via the Internet, as well as through various mobile devices (laptops, tablets, mobile phones).

\section{Conclusion}

Business intelligence analytics are a key aspect in developing the competitiveness of different universities and achieving sustainable development in the process of monitoring and controlling the processes involved in the processing of big educational data. The observations in the conducted survey allow the conclusion to be made that the introduction of a BI platform at the University of Forestry will contribute to supporting associative data research and detailed visualization of dynamic processes in the educational institution in order to rethink the university's vision and present its positions among educational structures at the international level. Such an approach will lead to a direct interaction between the established information system that is currently operating and servicing the functional units of the organization in order to increase the efficiency of data and information processing, generating emergency analysis and reports across all units for timely decision-making, which, as a result, will lead to an increase in the quality of the products and services provided, a reduction in costs and an increase in the efficiency of the entire organization. In this sense, academic management must maintain and develop a similar strategy in the management practice of the University of Forestry in the long term.

Recommendations and Future Studies

The performed analysis and obtained results are a logical basis for the future development of an approach for the introduction of business analysis technology for monitoring and control over large volumes of data generated at the University of Forestry, which, as a result, will improve the process of supporting decision-making and the development of the university's vision. In this sense, if the university's senior management supports the implementation process, the attention of our future developments will have to be focused on improving the competencies related to the use of tools in business analysis and management systems. It will be necessary to examine the competence of the University staff to work with business intelligence and management technology, the need for training, as well as the speed of 
their learning, in order to build basic skills for the specific work with the BI platform, so that university staff can have the capacity to analyse the information obtained and interpret the data in the context of an associative relationship and to draw direct relationships between the data and the information.

\section{References}

Clark, T. D., Jones, M. C., Armstrong, C. P. (2007). The Dynamic Structure of Management Support Systems: Theory development, research focus and directions. MIS Quarterly.

Dell'Aquila, C., Tria, F. Di, Lefons, E., Tangorra, F. (2008). Business intelligence systems: a comparative analysis, WSEAS Transactions on Information Science \& Applications, Vol. 5, pp. 612-621.

Elbashir, M.Z., Collier, P.A. \& Davern, M.J. (2008). Measuring the effects of business intelligence systems: the relationship between business process and organizational performance. International Journal of Accounting Information Systems, 9(3), 135153.

Howson, C., Richardson, J., Sallam, R. \&Kronz, A. (2019). Magic quadrant for analytics and business intelligence platforms, Gartner, Retrieved from https://www.gartner.com/doc/3900992/magic-quadrant-analytics-business-intelligence.

IDC - International Data Corporation (2019). Forecasts Revenues for Big Data and Business Analytics Solutions Will Reach \$189.1 Billion This Year with Double-Digit Annual Growth Through 2022. Available at: https://www.idc.com/getdoc.jsp?containerId=prUS44998419.

Isik, O. (2009). Business intelligence success: An empirical evaluation of the role of BI capabilities and organization's decision environment. AMCIS 2009 Doctoral Consortium, 1-13.

Mladenova, M., Zhelyazova, B. (2016). Application of e-learning platform Blackboard Learn in the University of Forestry, Sofia, Bulgaria. Innovate \& Educate, Teaching \& Learning Conference by Blackboard, April, Groningen.

Mladenova, M., Kirkova, D., (2019). Use of Alumni Network by the University of Forestry as a Mechanism for Monitoring and Evaluation of Group Indicators from the Higher Education System, Intel Entrance. ISBN: 978-954-2910-92-3 (in Bulgarian)

Monfared, J., Akbari, Z. (2019). Using Business Intelligence Capabilities to Improve the Quality of Decision-Making: A Case Study of Mellat Bank, World Academy of Science, Engineering and Technology, International Journal of Economics and Management Engineering, Vol:13, No:2, 2019, ISNI:0000000091950263.

Muntean, M., Sabau, G., Bologa, A. R., Surcel T. and A. Florea (2010). Performance Dashboards for Universities, 2nd International Conference on Manufacturing Engineering, Quality and Production Systems.

Neykova, M., Zhelyazova, B. (2017). Contemporary Training Methods in the Field of Business Intelligence Decision Support Systems. 2nd Conference on Innovative Teaching Methods (ITM 2017), Bulgaria, pp. 134. ISBN 978-954-21-0930-3.

Ramakrishnan, T., Jones, M. C., \& Sidorova, A. (2012). Factors influencing business intelligence (BI) data collection strategies: An empirical investigation. Decision Support Systems, 52(2), 486-496.

Richardson, J., Sallam, R., Schlegel, K., Kronz, A., Sun J. (2020). Magic Quadrant for Analytics and Business Intelligence Platforms, Published 11 February 2020, ID G00386610. Retrieved from https://www.gartner.com/en/documents/3980852/magic-quadrant-for-analytics-and-business-intelligence-p.

Sallam, R., Howson, C., Idoine, C. (2017). Magic Quadrant for Business Intelligence and Analytics Platforms. Gartner, Inc. Shariat, M., \& Hightower Jr, R. (2007). Conceptualizing business intelligence architecture. Marketing Management Journal, $17(2), 40-46$

UL-Ain, N., Giovanni, V. \& DeLone, W. (2019). Business intelligence system adoption, utilization and success - A systematic literature review, Proceedings of the 52nd Hawaii International Conference on System Sciences, January 8 January 11, 2019, Grand Wailea, Maui.

Yeoh, W., \& Koronios, A. (2010). Critical success factors for business intelligence systems. Journal of computer information systems, 50(3), 23-32.

Wen-Chen, Hu, Kaabouch, N. (2014). Big Data Management. Technologies and Applications, IGI Global, USA.

Watson, H. J., \& Wixom, B. H. (2007). The current state of business intelligence. Computer, 40(9), 96-99.

Link to the university's financial statements available on the website: https://tinyurl.com/yyt7neew 